\title{
UMA VISÃO CONSERVADORA SOBRE O PLÁGIO? REFLEXÕES A PARTIR DE UM LEVANTAMENTO SOBRE A PERSPECTIVA DE UMA POPULAÇ̃̃O DE ALUNOS BRASILEIROS DO ENSINO MÉDIO
}

\author{
CHRISTIANE COELHO SANTOS ${ }^{*}$ \\ https://orcid.org/0000-0001-9467-3334
}

SONIA MARIA RAMOS DE VASCONCELOS" ${ }^{* *}$

https://orcid.org/0000-0001-6315-6510

RESUMO: Este estudo oferece uma perspectiva sobre o plágio no âmbito do ensino de ciências na educação básica. Os alunos pesquisados estão inseridos em uma instituição federal brasileira e os resultados são apresentados em diálogo com pesquisa anterior, com professores de ciências, na mesma instituição. Realizamos uma survey em 2016 com uma população de 427 estudantes da $3^{a}$ série do ensino médio, 29,6\% do total de discentes nessa mesma série em todos os campi da instituição. Do total de 427 participantes, 98,1\% responderam e nos permitiram oferecer um panorama sobre suas percepções e atitudes sobre o plágio na escola. Os resultados indicam, nessa população pesquisada, uma visão sobre o plágio talvez mais conservadora do que se esperaria para alunos do ensino médio. Além da pesquisa oferecer uma perspectiva sobre o problema na educação em ciências, faz uma provocação sobre a urgência de investigações sobre a prática de plágio na educação básica.

Palavras-chave: Plágio. Educação em ciências. Educação básica.

\section{¿UNA VISIÓN CONSERVADORA SOBRE EL PLAGIO? REFLEXIONES} A PARTIR DE UNA ENCUESTA SOBRE LA PERSPECTIVA DE UNA POBLACIÓN DE ALUMNOS BRASILEÑOS DE LA ENSEÑANZA MEDIA

RESUMEN: Este estudio ofrece una perspectiva sobre el plagio en la enseñanza de las ciencias en la escuela. Los participantes son estudiantes en una institución federal brasileña, y los resultados se presentan en diálogo con una investigación anterior, con profesores de ciencias, en la misma institución. Realizamos una encuesta en 2016 con 427 alumnos del tercer año de la enseñanza

\footnotetext{
*Doutora em Ciências - Educação, Gestão e Difusão em Biociências, Instituto de Bioquímica Médica Leopoldo de Meis (IBqM), UFRJ. Colaboradora do Laboratório de Ética em Pesquisa, Comunicação Científica e Sociedade (LECCS), IBqM/UFRJ. Professora no Departamento de Biologia e Ciências do Colégio Pedro II. E-mail:<christiane.santos@cp2.g12.br>.

* *Doutora em Ciências - Educação, Gestão e Difusão em Biociências, Instituto de Bioquímica Médica Leopoldo de Meis (IBqM), UFRJ, Professora no Programa de Educação, Gestão e Difusão em Biociências (IBqM), UFRJ. Coordenadora do Laboratório de Ética em Pesquisa, Comunicação Científica e Sociedade (LECCS), IBqM/UFRJ.

E-mail:< svasconcelos@bioqmed.ufrj.br >.
}

\footnotetext{
' Colégio Pedro II, Departamento de Biologia e Ciências, Rio de Janeiro, RJ - Brasil.

" Universidade Federal do Rio de Janeiro, Instituto de Bioquímica Médica Leopoldo de Meis (IBqM), Programa de Educação, Gestão e Difusão em Biociências, Rio de Janeiro, RJ - Brasil.
} 
media, el 29,6\% de alumnos del mismo año en todos los campus de la institución. De los 427 participantes, el 98,1\% respondieron y nos posibilitaron ofrecer un panorama acerca de sus percepciones y actitudes sobre el plagio en la escuela. Los resultados indican, en esa población encuestada, que el plagio se ve tal vez de una manera más conservadora de lo que se esperaba para los estudiantes de secundaria. Además de ofrecer una perspectiva sobre el problema en la enseñanza de las ciencias, esta investigación es un recordatorio provocativo de la urgencia de la investigación sobre la práctica del plagio en la escuela.

Palabras clave: Plagio. Educación en ciencias. Educación básica.

\section{A CONSERVATIVE VIEW ON PLAGIARISM? REFLECTIONS FROM A SURVEY ON THE PERSPECTIVE OF A POPULATION OF BRAZILIAN HIGH SCHOOL STUDENTS}

ABSTRACT: This study offers a perspective on plagiarism in science education at school. The research participants are students enrolled in a Brazilian federal institution, and the results are presented in dialogue with previous research, with science teachers, in the same institution. We conducted a survey in 2016 with a population of 427 students in the $3 \mathrm{rd}$ grade of high school, $29.6 \%$ of the total of students at this same grade in all campuses of the institution. Of the total of 427 participants, $98.1 \%$ responded and allowed us to give some insight into their perceptions and attitudes about plagiarism at school. For this population surveyed, results indicate that plagiarism is viewed perhaps in a more conservative way than would be expected for high school students. In addition to offering a perspective on the problem in science education, this research is a provocative reminder of the urgency of investigations into plagiarism practices in basic education.

Keywords: Plagiarism. Science education. Basic education. 


\section{INTRODUCְÃ $0^{1}$}

Segundo o etimólogo Antonio Geraldo Da Cunha (1997, p. 611) o termo plágio - "ato ou efeito de imitar, de apresentar, como sua, obra de outra pessoa" vem do latim plagium, o qual por sua vez deriva do termo grego plágion. Essa origem da palavra remetendo ao grego e não ao latim concorda com a colocação de Skandalakis e Mirilas (2004), de que, apesar da etimologia da palavra plágio ser frequentemente relacionada ao latim, há um equívoco nessa atribuição. Os autores descrevem que "... plagiarism comes from the Latin plagiarius, meaning kidnapper. However, in classical Latin, plagiarius never refers to a plagiarist... ironically, the etymology of plagiarism is often wrongly attributed" (p.1022). Independentemente do entendimento, ambas as origens remetem a um significado que corresponde a algo equivocado, incorreto. Segundo Christofe (1996), no direito romano, o sentido de plagium é atribuído a uma apropriação fraudulenta de escravos; enquanto que para a palavra grega plágion, a mesma autora atribui o sentido de oblíquo, tortuoso, astucioso.

Christofe (1996) indica que a expansão do termo plagium para a associação com o roubo de textos escritos é creditada ao poeta Marcus Valerius Marcialis, que nasceu na Espanha em 39 ou 40 d.C., mas viveu muitos anos em Roma. Utilizando as mesmas normas legais para a posse indevida de escravos, Marcialis solicita a propriedade de versos, criados por ele, que estavam sendo recitados por outro poeta (CHRISTOFE, 1996). Podemos considerar a manifestação de Marcialis o marco inicial do uso do termo plágio com conotação de apropriação indevida da produção intelectual de outrem e, portanto, da relação direta entre plágio e autoria. Entretanto, até o século XVIII, o reconhecimento do autor como proprietário de sua obra não era uma preocupação daquela sociedade e essa noção de propriedade era muito vaga (KROKOSCZ, 2015). Nesse cenário, possíveis “empréstimos" realizados por autores tão significativos da literatura mundial, como William Shakespeare (1564-1616), por exemplo, não representavam uma apropriação fraudulenta. Vale destacar que, "até então, a produção intelectual era trabalho de escritores, muitas vezes copistas, cuja ação era naturalmente aceita e compartilhada socialmente" (KROKOSCZ, 2015, p. 50).

A preocupação em conferir ao autor de uma obra a propriedade sobre a mesma surge, na Era Moderna (1453-1789), estritamente ligado a outros fatos históricos marcantes, que incluem a invenção da imprensa em meados do século XV, o aumento do número de pessoas que passam a dominar a leitura e a escrita na Europa (CHARTIER, 2009), a publicação do Estatuto da Rainha Ana, em 1710, na Inglaterra, e dos Decretos Revolucionários Franceses de 1791 e 1793 (ZANINI, 2014).

Dentre esses documentos o estatuto inglês de 1710 foi um marco transitório de importância, pois, "pela primeira vez, o termo autor aparece como proprietário de um direito” (SOUZA, 2013, p. 168). Segundo Zanini (2014), entretanto, o direito do autor só teria sido efetivamente consagrado com os Decretos Franceses de 1791 e 1793, já no início da Idade Contemporânea. Por estes, os autores teriam o direito sobre a reprodução e exploração de suas obras literária, musical e artística, durante toda a vida, o que seria extensivo aos seu herdeiros, por um período de 10 anos. A importância do Estatuto de 1710 e dos decretos franceses é também destacada por Paranaguá e Branco (2009), no processo histórico de regulação ampla dos direitos autorais. Porém, esses mesmos autores também sinalizam o papel da Convenção 
de Berna, realizada em 1886, na cidade Suiça. Segundo Paranaguá e Branco (2009. p.17), essa Convenção que definiu "padrões de proteção dos direitos a serem concedidos aos autores de obras literárias, artísticas e científicas”.

A concretização da noção do autor como proprietário de sua obra (literária ou não), e que ficou refletida nas legislações dos séculos XVIII e XIX, vinculou assim o conceito de plágio que encontramos hoje em diferentes dicionários. Esse conceito pode ser exemplificado por aquele definido por Koogan e Houaiss (2000, p. 1265) como "ação do plagiário; cópia, mais ou menos disfarçada, de obra alheia”. O plágio, portanto, não é um fenômeno que poderíamos considerar recente na cultura ocidental. Entretanto, essa prática ganha contornos particulares quando está inserido no contexto acadêmico. Como declara Zanini (2016, p. 52),

o pressuposto fundamental do plágio é a obtenção pelo plagiador de vantagens de ordem não patrimonial, tais como a fama, o reconhecimento e o prestígio, agregando valores à sua personalidade, em desrespeito ao direito de paternidade de outrem.

No âmbito acadêmico, soma-se a essas questões e conceitos o significado que a autoria adquire ao longo do tempo. Na ciência, a autoria de uma obra não dá ao autor apenas o direito de propriedade. Atrelada a ela está à credibilidade diante dos pares e demais leitores. Como demonstra Merton (1968) em seu clássico The Mathew Effect in Science (1968), além da credibilidade, está o crédito e o reconhecimento que se acumulam na comunidade científica, retroalimentados pelo sistema de recompensas da ciência. Segundo Merton (1968, p.57, tradução nossa), esse reconhecimento não é equânime para os autores científicos:

Em artigos em coautoria por homens de reputação decididamente desigual, um outro laureado em física relata, "o homem mais conhecido obtém mais crédito, uma quantidade excessiva de crédito. Nas palavras de um laureado em química: "Quando as pessoas veem meu nome em um artigo, eles são capazes de lembrá-lo e de não lembrar dos outros nomes". Um laureado em fisiologia e medicina descreve seu padrão de resposta sobre trabalhos de autoria conjunta. [Ele relata que] Você geralmente percebe o nome com o qual você é familiar. Mesmo que seja rápido, é aquele que lhe chama mais a atenção. Em alguns casos, todos os nomes são desconhecidos para você e são praticamente anônimos. Mas o que você observa é a seção de agradecimentos no final do artigo para a pessoa sênior que ofereceu orientação e estímulo. Então você dirá: Esse trabalho surgiu do laboratório de Greene, ou do laboratório do fulano. Você lembra é disso, mais do que a longa lista de autores.".

Nesse contexto de autoria científica, a originalidade de contribuições tem um papel crucial. O plágio seria uma forma de roubo da criatividade de outrem e de enganar os pares (MADDOX, 1995), criando uma falsa impressão sobre a origem do que está sendo apresentado (ANDERSON; STENECK, 2011). Essa violação ética atinge diretamente um dos valores mais cultivados na atividade científica: a confiança entre os pares. Como afirmam Diniz e Terra (2014, p. 27): “o crédito de uma obra acadêmica não expressa apenas o reconhecimento da criação, mas a delegação de responsabilidade pelo que é apresentado sob a rubrica de pesquisa científica." 
Nas ciências, o plágio constitui um dos três eixos que definem a má conduta em pesquisa, segundo a Federal Research Misconduct Policy, publicada em 2000, pelo Office of Research Integrity (ORI) dos Estados Unidos, amplamente aceita pela comunidade acadêmica mundial. Nesse documento, onde "Research misconduct is defined as fabrication, falsification, or plagiarism in proposing, performing, or reviewing research, or in reporting research results.", o plágio é determinado como: "the appropriation of anotherperson's ideas, processes, results, or words without giving appropriate credit." (OFFICE OF SCIENCE AND TECHNOLOGY POLICY, 2000). Várias questões sobre integridade em pesquisa tiveram papel relevante na construção desse conceito, como aquelas associadas a condutas consideradas antiéticas na ciência, que ganharam foco, especialmente, a partir da década de 1980 (MONTGOMERY; OLIVER, 2009). O número de publicações abordando o plágio vem, portanto, crescendo ao longo do tempo, uma vez que é parte integrante dessas preocupações.

\section{UM PANORAMA SOBRE O INTERESSE ACADÊMICO SOBRE PLÁGIO, A PARTIR DE BASES DE DADOS}

O Google Ngram Viewer (http://books.google.com/ngrams) oferece um panorama sobre a presença do termo plagiarism em livros que compõem a base de dados do Google Books, entre os anos 1960 e 2008 (limite dado pelo programa em busca realizada em 2017). Essa tendência pode ser claramente observada, como mostra o gráfico a seguir (Figura 1):

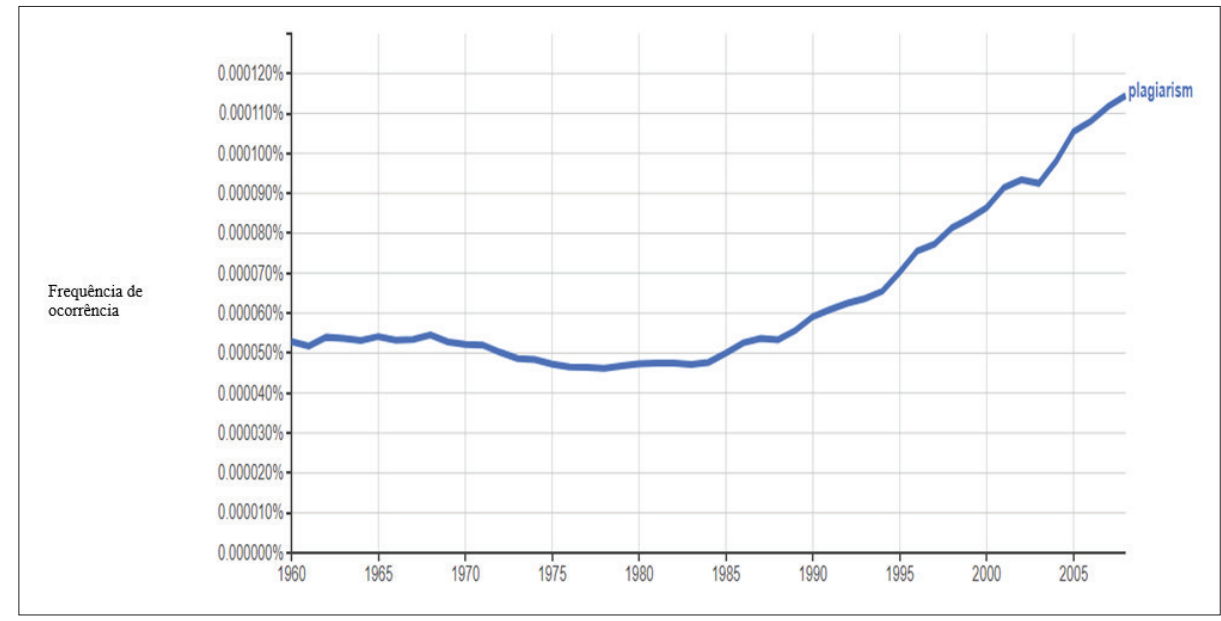

Figura 1. Frequência de ocorrência da palavra plagiarism entre os anos de 1960 e 2008 nos livros que compõem a base de dados Google Books. Fonte: http://books.google.com/ngrams. Acesso em: 21 out. 2017.

Essa tendência nos faz considerar que, dentre outros aspectos, o aumento da frequência do termo plagiarism em livros sugere um interesse maior pelo assunto, embora não necessariamente um aumento da produção científica relacionada ao tópico. Sobre um pequeno panorama associado a essa produção, uma busca por plagiarism em três bases de dados voltadas para a literatura científica: Scopus, Web of Science e Google Acadêmico (ou Google Scholar) permite uma visão acadêmica mais específica e complementar. ${ }^{3}$ 
$\mathrm{Na}$ base Scopus, ${ }^{4}$ ao direcionarmos a busca da palavra plagiarism para o título da publicação - 1960-2008 - observamos um crescimento, principalmente após o ano 2000 (Figura 2).

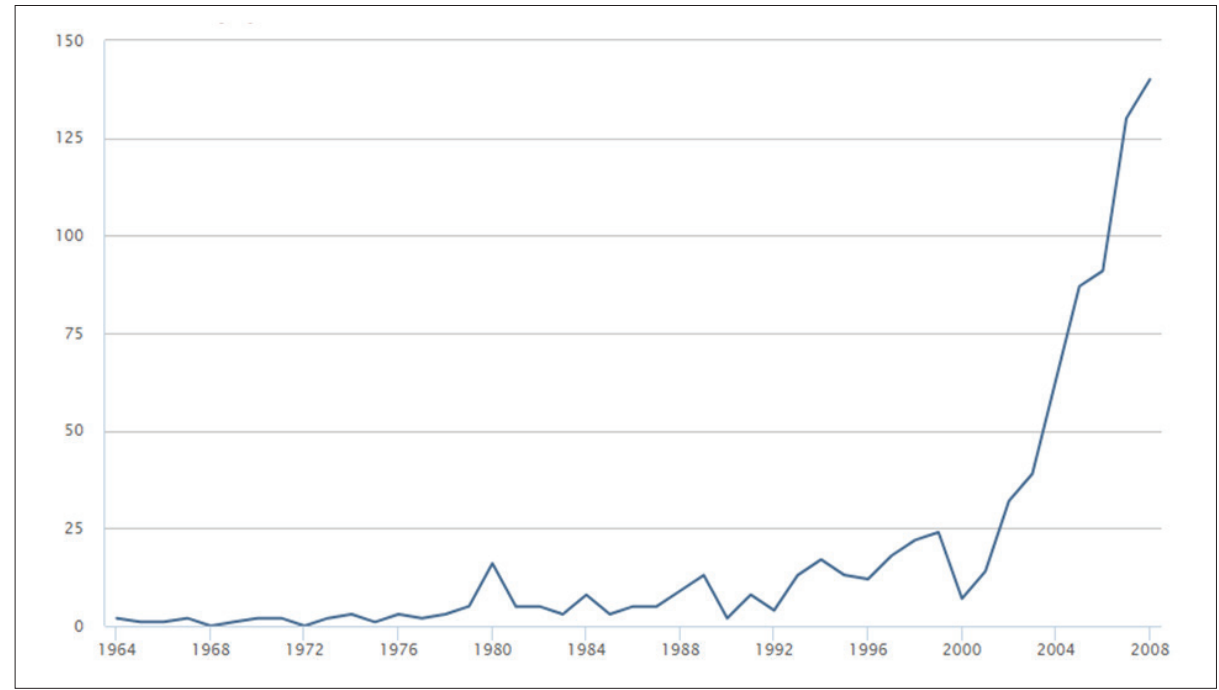

Figura 2. Variação do número de publicações listadas na base de dados Scopus, entre os anos de 1960 e 2008, que apresentam a palavra plagiarism no título. Fonte: https://www-scopus.ez29.capes.proxy. ufrj.br/search/form.uri?display=basic Acesso em: 29/10/2017.

A mesma pesquisa na Web of Science $(W O S)^{5}$ revela padrão similar de crescimento do número de publicações com a palavra plagiarism, apenas no título (Figura 3).

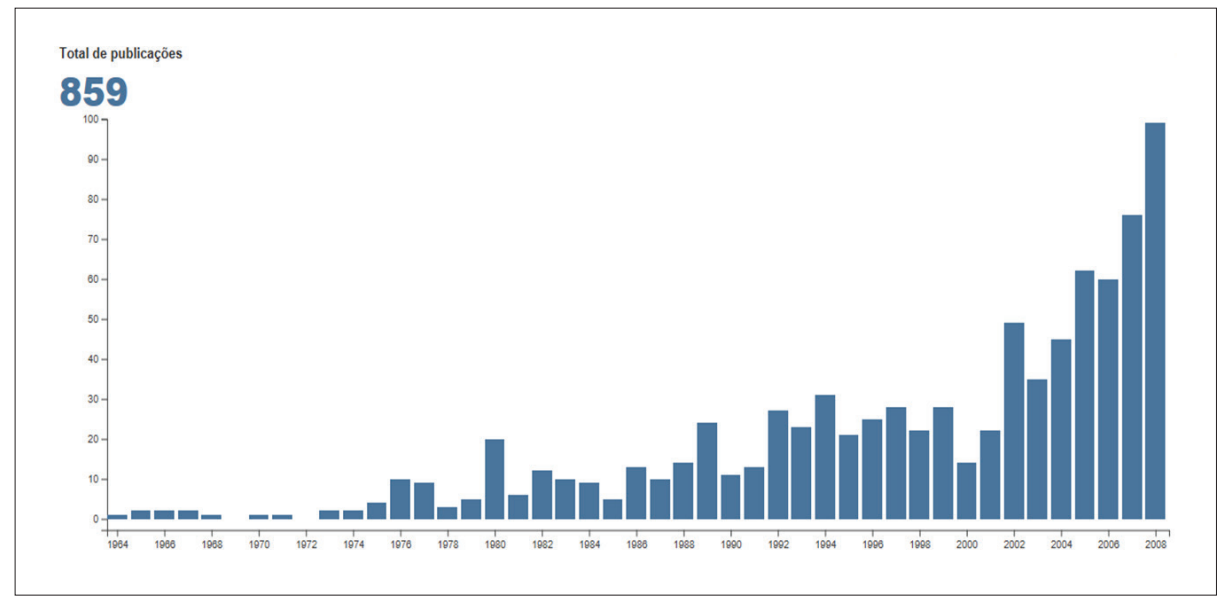

Figura 3. Variação do número de publicações listadas na base de dados Web of Science (WOS), entre os anos de 1960 e 2008, que apresentam a palavra plagiarism no título. Fonte: http://appswebofknowledge.ez29.capes.proxy.ufrj.br/WOS_GeneralSearch_input.do?product = WOS\&search mode $=$ GeneralSearch\&SID = 4ELkfsJOK3RtG6ifgȳ2\&preferences $\bar{S}$ aved Acesso em: 21 out. 2017. 
$\mathrm{Na}$ base de dados do Google Acadêmico ou Google Scholar $(G S)^{6}$ a mesma pesquisa também revela um crescimento de publicações sobre plágio, após a década de 1980, que se acentua, nos anos 2000 (Figura 4).

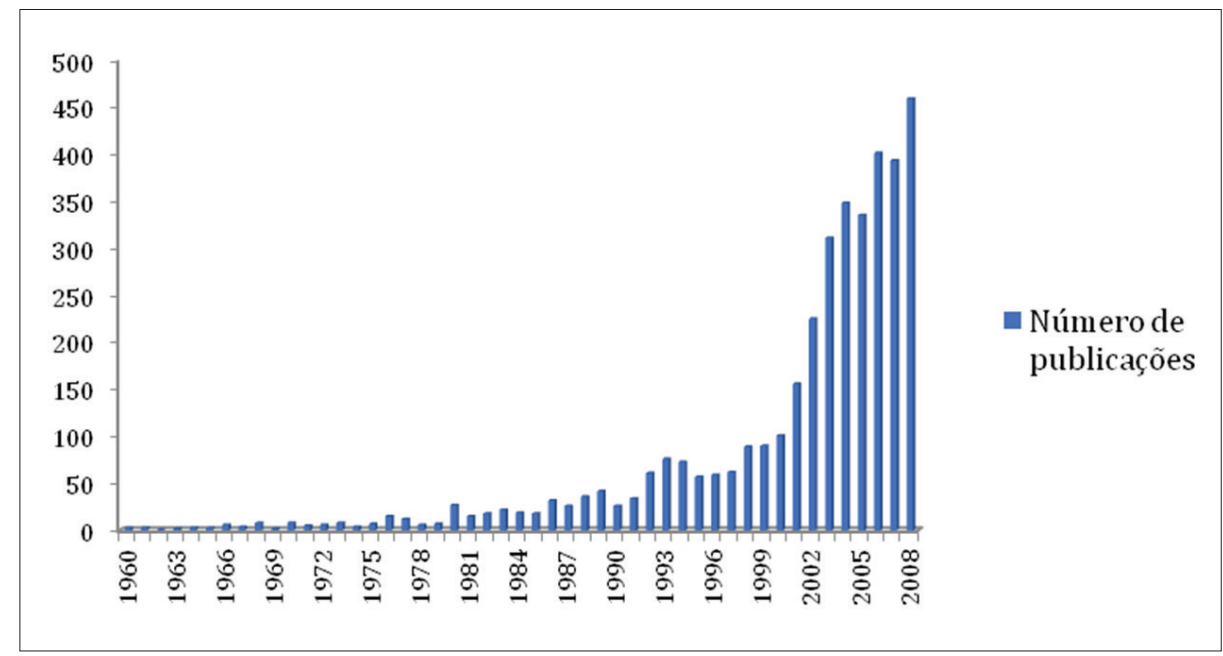

Figura 4. Variação do número de publicações listadas na base de dados Google Acadêmico, entre os anos de 1960 e 2008, que apresentam a palavra plagiarism no título. Gráfico produzido a partir de dados obtidos em: https://scholar.google.com.br Acesso em: 24/10/2017.

À esse visível aumento de atenção da comunidade acadêmica sobre o plágio, acrescenta-se a perspectiva de Montgomery e Oliver (2009). Ao realizarem uma análise (a partir de 1975) das "atividades e atores envolvidos na articulação e difusão de diretrizes para a conduta científica ética histórica” (p. 137), revelam três momentos distintos: o período pré-1975, quando os preceitos Mertonianos vigoravam mais fortemente na ciência; entre 1975 e 1990, quando a má conduta passou a ser o foco; e a partir de 1990, momento em que o protagonismo é dado à promoção da integridade na pesquisa - tudo isso refletido em discussões e contribuições prevalentes em língua inglesa.

Nesse panorama, o artigo "Confronting misconduct in Science in the 1980s and 1990s: what has and has not been accomplished?" (STENECK, 1999), publicado ao final do século XX, apresenta informações complementares. A partir de 1985, as questões relacionadas à má conduta na atividade científica passaram a desafiar padrões de autorregulação da ciência, provocando ações institucionais com o intuito de promover a integridade na pesquisa, especialmente nos Estados Unidos (STENECK, 1999). Com o tempo, outros países, como na Europa e alguns na Ásia, foram ampliando o panorama de ações (VASCONCELOS et al., 2009).

Como já sinalizado, essa promoção de normas de conduta responsável na pesquisa se intensificou a partir de 1990, levando a uma atenção acadêmica cada vez mais marcada ao plágio, aspecto que pode ser verificado em buscas pelo termo plagiarism nas mesmas bases citadas anteriormente, porém ampliadas até anos mais recentes (SANTOS, 2018). 
Olhando para o plágio sob as lentes da educação no ensino básico, precisamente no âmbito do ensino médio e da educação em ciências, a mesma apreciação da literatura acadêmica nos apresenta um panorama bem distinto do relatado anteriormente. Essa produção é bem menos expressiva. Em um levantamento comparativo realizado em outubro de 2017, no Scopus, Web of Science e Google Acadêmico o número de artigos produzidos entre 1960 e 2016 para os termos plagiarism and education, plagiarism and high school e plagiarism and science education é bem reduzido quando comparado àquele para plagiarism. Esse panorama específico indica que a produção acadêmica relacionada ao plágio é bem menor quando o termo é vinculado a education e depois, mais acentuadamente, quando vinculado a high school e science education, independentemente se essas podem ser encontradas separadas ou como palavras compostas (Tabela 1).

Tabela 1. Número de publicações encontradas nas bases bibliográficas Scopus, Web of Science e Google Acadêmcio, entre os anos de 1960 e 2016, a partir da presença no título dos termos plagiarism, plagiarism and education, plagiarism and high school, e plagiarism and science education. High school e science education são apresentados também como palavras compostas (através do uso das aspas) Dados obtidos em:https://www-scopus.ez29.capes.proxy.ufrj.br/search/form.uri?display=basic;http://appswebofknowledge.ez29.capes.proxy.ufrj.br/WOS_GeneralSearch_input.do?product = WOS\&search mode $=$ GeneralSearch\&SID =4E84DjzZiqVhG6wDË01\&preferencesSaved =e https://scholar.google. com.br/ Acesso em: 30 out. 2017.

\section{$1960-2016$}

\begin{tabular}{lccc|}
\hline & Scopus & Web of Science & $\begin{array}{c}\text { Google } \\
\text { Acadêmico }\end{array}$ \\
\hline Plagiarism & 2293 & 1921 & 8370 \\
\hline Plagiarism and Education & 68 & 55 & 135 \\
\hline Plagiarism and High School & 3 & 3 & 10 \\
\hline Plagiarism and "High School” & 3 & 3 & 10 \\
\hline Plagiarism and Science Education & 3 & 5 & 5 \\
\hline Plagiarism and “Science Education" & 2 & 2 & 2 \\
\hline
\end{tabular}

Diante dessa baixa produção, uma busca por esses descritores no título, resumo e palavras-chave no Scopus e Web of Science (Tabela 2) amplia a visão das contribuições relacionados à temática. 
Tabela 2. Número de publicações encontradas nas bases bibliográficas Scopus e Web of Science, entre os anos de 1960 e 2016, a partir da presença no título, no resumo e nas palavras-chave dos termos plagiarism, plagiarism and education, plagiarism and high school, e plagiarism and science education. High school e science education são apresentados também como palavras compostas (através do uso das aspas) Dados obtidos em: https://www-scopus.ez29.capes.proxy.ufrj.br/search/form.uri?display = basic e http://appswebofknowledge.ez29.capes.proxy.ufrj.br/WOS GeneralSearch_input.do?product $=$ WOS\&search mode $=$ GeneralSearch\&SID =4E84DjzZiqVhG6wDĒE1\&preferencesSaved = Acesso em: 31 out. $201 \overline{7}$.

$1960-2016$

\begin{tabular}{|lcc|}
\hline & Scopus & Web of Science \\
\hline Plagiarism & 4822 & 3200 \\
\hline Plagiarism and Education & 950 & 424 \\
\hline Plagiarism and High School & 75 & 49 \\
\hline Plagiarism and “ High School “ & 32 & 19 \\
\hline Plagiarism and Science Education & 223 & 75 \\
\hline Plagiarism and “Science Education” & 20 & 9 \\
\hline
\end{tabular}

Diante dessa reduzida produção acadêmica, observamos ainda que dentre as publicações indicadas pelas bases Scopus e Web of Science sobre plágio vinculado à educação em ciências (Tabela 2), o foco se mantém no ensino superior. Dentre essas publicações, há trabalhos cuja atenção são os softwares para detecção de plágio (CEBRIÁN; ALFONSECA; ORTEGA, 2009; DOMIN; POHL; KRAUSE, 2016; JI; WOO; CHO, 2007; LIU; XU; OUYANG, 2015) e outros que trazem o ponto de vista dos estudantes sobre o plágio, como o dos autores Arda (2012) e Chuda et al. (2012). O autoplágio é discutido por Moskovitz (2015), por exemplo. A inserção de estudantes de diferentes países no meio acadêmico americano e as consequências desse para a escrita científica e o plágio é discutido por Heitman e Litewka (2011).

O Brasil reflete essa escassez de produção relacionada especificamente a essa temática na educação em ciências e na educação básica, o que, no nosso entendimento, é algo bastante preocupante. A cultura da repetição de saberes e da cópia na escola apresenta-se como desafio para um ambiente que deve estimular a criatividade -característica decisiva para o desenvolvimento cultural, científico e econômico dos países (SANTOS, 2018).

A lacuna presente na produção acadêmica destacada anteriormente, foi discutida em trabalho apresentado em 2018, no V Brazilian Meeting on Research Integrity, Science and Publication Ethics (V BRISPE). ${ }^{7}$ Nessa apresentação, indicamos que apenas 19 publicações registradas na base Scopus foram identificadas para o período 2008-2017, combinando plágio (plagiarism) e “educação em ciências" ("science education"). Essa lacuna internacional reflete a também existente no Brasil. Outro fator que deve ser considerado é a preocupação, que compartilhamos, sobre a importância da educação no contexto da conduta responsável em pesquisa. Como argumenta Grinnell (2013, p.700, tradução nossa) 
A introdução antecipada da educação em conduta responsável em pesquisa... no currículo de ciências deve ser considerada para experimentos em laboratórios de ciências e feiras de ciências. Fazer isso poderia promover oportunidades únicas para esclarecer impressões errôneas por parte dos alunos (e de seus professores) sobre a natureza e a prática da ciência.

É nesse contexto que se insere este artigo: Ao mesmo tempo em que esse panorama apresentado revela uma escassez de estudos acadêmicos que abordam o plágio na educação em ciências, também indica a importância de se inserir, ainda na educação básica, temáticas relacionadas à conduta responsável na pesquisa (BRETAG, 2019).

Neste trabalho, apresentamos resultados de um estudo realizado com alunos de ensino médio de uma escola da rede federal de ensino do Brasil. ${ }^{8}$ Investigou-se a percepção dos alunos sobre alguns aspectos relacionados ao plágio, comparando-a, quando possível, a resultados anteriores obtidos em pesquisa feita com professores de biologia, física e química da mesma instituição e já publicado sob o título "Going Beyond Academic Integrity Might Broaden our Understanding of Plagiarism in Science Education: A Perspective from a Study in Brazil" (SANTOS et al., 2017).

\section{METODOLOGIA}

Esta é uma pesquisa de natureza quantitativa (MCMILLAN; SCHUMACHER, 2010) que tem como instrumento um questionário baseado em questões utilizadas em survey anterior, conforme descrito em (SANTOS et al., 2017). Esse questionário semiestruturado foi composto por sete afirmações, com cinco opções de resposta cada, seguindo o padrão de uma Escala "tipo" Likert (1934). Do total de questões, as quatros primeiras objetivavam verificar a compreensão dos alunos sobre o conceito de plágio e eram bastante semelhantes àquelas já aplicadas em survey anterior com os professores (SANTOS et al., 2017). A quinta trazia uma afirmação sobre a prática do plágio por parte dos alunos e os colocava como sujeitos ativos no processo. As duas últimas afirmações abordavam, novamente, aspectos constantes do instrumento utilizado para os professores, como a orientação recebida sobre plágio e o estímulo à criatividade ou à repetição no ensino de Biologia, Física e Química. (Figura 5). 


\section{PESQUISA ACADÊMICA}

O plágio é uma preocupação de educadores brasileiros e estrangeiros. Gostaríamos de ter sua opinião sobre essa prática na escola.

Para cada assertiva da coluna I marque a opção que melhor contempla sua opinião na coluna II. Fique à vontade para fazer comentários no final.

\begin{tabular}{|c|c|}
\hline $\begin{array}{l}\text { 1. A utilização de ideias do outro e a apropriação das mes- } \\
\text { mas sem a devida atribuição à fonte/autoria é plágio. }\end{array}$ & $\begin{array}{l}\text { ( ) concordo } \\
\text { ( ) concordo parcialmente } \\
\text { ( ) não sei avaliar } \\
\text { ( ) discordo parcialmente } \\
\text { ( ) discordo }\end{array}$ \\
\hline $\begin{array}{l}\text { 2. A utilização da produção intelectual escrita do out- } \\
\text { ro (frases/trechos de parágrafos, textos completos) e a } \\
\text { apropriação da mesma sem a devida atribuição à fonte/ } \\
\text { autoria é plágio. }\end{array}$ & $\begin{array}{l}\text { ( ) concordo } \\
\text { ( ) concordo parcialmente } \\
\text { ( ) não sei avaliar } \\
\text { ( ) discordo parcialmente } \\
\text { ( ) discordo }\end{array}$ \\
\hline $\begin{array}{l}\text { 3. A cópia integral (“clonagem") de textos da Inter- } \\
\text { net não é plágio caso eu cite a fonte. }\end{array}$ & $\begin{array}{l}\text { ( ) concordo } \\
\text { ( ) concordo parcialmente } \\
\text { ( ) não sei avaliar } \\
\text { ( ) discordo parcialmente } \\
\text { ( ) discordo }\end{array}$ \\
\hline $\begin{array}{l}\text { 4. A cópia parcial de textos (frases, trechos de } \\
\text { parágrafos ou parágrafos inteiros) da Internet não é } \\
\text { plágio caso eu cite a fonte. }\end{array}$ & $\begin{array}{l}\text { ( ) concordo } \\
\text { ( ) concordo parcialmente } \\
\text { ( ) não sei avaliar } \\
\text { ( ) discordo parcialmente } \\
\text { ( ) discordo }\end{array}$ \\
\hline $\begin{array}{l}\text { 5. "Diante de uma tarefa de pesquisa [os alunos] não leem } \\
\text { sobre o assunto, não raciocinam... apenas copiam e colam } \\
\text { textos de terceiros da Internet.". (Documento da Ordem } \\
\text { dos Advogados do Brasil - OAB - que discute o crescimen- } \\
\text { to da prática de plágio no ensino médio e superior, 2011). }\end{array}$ & $\begin{array}{l}\text { ( ) concordo } \\
\text { ( ) concordo parcialmente } \\
\text { ( ) não sei avaliar } \\
\text { ( ) discordo parcialmente } \\
\text { ( ) discordo }\end{array}$ \\
\hline $\begin{array}{l}\text { 6. No ensino médio eu recebi informações de meus } \\
\text { professores sobre como evitar o plágio em trabalhos de } \\
\text { pesquisa. }\end{array}$ & $\begin{array}{l}\text { ( ) sempre } \\
(\text { ) quase sempre } \\
\text { ( ) às vezes } \\
\text { ( ) raramente } \\
(\text { ) nunca }\end{array}$ \\
\hline $\begin{array}{l}\text { 7. O ensino de biologia, física e química na escola } \\
\text { estimula mais o desenvolvimento da criatividade do que } \\
\text { a repetição por parte do aluno. }\end{array}$ & $\begin{array}{l}\text { ( ) concordo } \\
\text { ( ) concordo parcialmente } \\
\text { ( ) não sei avaliar } \\
\text { ( ) discordo parcialmente } \\
\text { ( ) discordo }\end{array}$ \\
\hline & \\
\hline
\end{tabular}

Figura 5. Questionário semiestruturado disponibilizado aos alunos da $3^{\mathrm{a}}$ série do ensino médio participantes da survey. 
O questionário foi aplicado a uma população de 427 estudantes da $3^{\text {a }}$ série do ensino médio, matriculados em dois campi constituintes de uma escola da rede federal de ensino do Brasil (estado do Rio de Janeiro), no ano de 2016, número correspondente a 29,6\% do total de discentes (1441) pertencentes a essa série no colégio. Da totalidade de questionários disponibilizados, 419 alunos concordaram em participar da survey, o que correspondeu a $98,1 \%$ da população e a $29 \%$ do total de alunos da série, em todos os campi da instituição. Em um cálculo amostral para amostras finitas, seria necessário, aproximadamente, um mínimo de 207 participantes (ISRAEL, 1992), para considerarmos a amostra representativa, como indicado na Tabela 3; neste trabalho, portanto, a amostra foi representativa dessa população de estudantes:

Tabela 3. Cálculo amostral com precisão de $\pm 5 \%, \pm 7 \%$ e $\pm 10 \%$, sendo 0 nível de confiança de $95 \%$ e $\mathrm{P}=0,5$

\begin{tabular}{c|ccc}
\multirow{2}{*}{$\begin{array}{c}\text { TAMANHO DA } \\
\text { POPULACุÃO }\end{array}$} & \multicolumn{1}{c}{ TAMANHO DA AMOSTRA (N) PARA A PRECISÃO (E) DE: } \\
\cline { 2 - 4 } 100 & $\pm 5 \%$ & $\pm 7 \%$ & $\pm 10 \%$ \\
\hline 125 & 81 & 67 & 51 \\
\hline 150 & 96 & 78 & 56 \\
\hline 175 & 110 & 86 & 61 \\
\hline 200 & 122 & 94 & 64 \\
225 & 134 & 101 & 67 \\
\hline 250 & 144 & 107 & 70 \\
\hline 275 & 154 & 112 & 72 \\
\hline 300 & 163 & 117 & 74 \\
\hline 325 & 172 & 121 & 76 \\
\hline 350 & 180 & 125 & 77 \\
\hline 375 & 187 & 129 & 78 \\
\hline 400 & 194 & 132 & 80 \\
\hline 425 & 201 & 135 & 81 \\
\hline & 207 & 138 & 82 \\
\hline
\end{tabular}

Fonte: ISRAEL, 1992. 
Fórmula para o cálculo amostral (YAMANE, 1967, p.886 apud ISRAEL, 1992) utilizada na Tabela 3:

$$
\begin{aligned}
& \eta=N \div 1+N(\mathrm{e}) 2 \\
& \text { onde: } \\
& \eta=\text { tamanho da mostra } \\
& N=\text { tamanho da população } \\
& \text { e }=\text { nível de precisão }
\end{aligned}
$$

O questionário foi aplicado pela primeira autora deste artigo em três diferentes dias do mês de abril de 2016, nas 12 turmas da $3^{\text {a }}$ série do ensino médio no primeiro campus amostrado e em 9 das 10 turmas, em junho do mesmo ano, no segundo campus. Todos os alunos receberam o questionário durante a parte final ou inicial de uma aula de Biologia.

O procedimento de aplicação sempre foi iniciado com uma rápida explicação sobre a pesquisa. Em seguida, os alunos recebiam o Termo de Assentimento, que era lido pela primeira autora, sendo esclarecidas eventuais dúvidas dos participantes. Após a assinatura e devolução do Termo de Assentimento pelos alunos, esses recebiam o questionário. Antes que o respondessem, foi oferecida uma breve orientação sobre o padrão de respostas pela Escala tipo Likert. Os dados obtidos nos dos dois campi amostrados foram então plotados e analisados graficamente.

$\mathrm{Na}$ análise dos resultados buscou-se, na medida do possível, dialogar com resultados de pesquisa anterior, que envolveu respostas de professores de Biologia, Física e Química da mesma Instituição, acerca da mesma temática. (SANTOS et al., 2017). Porém, não foi verificado se os alunos respondentes tiveram aulas com os professores previamente amostrados. É provável que esse fato tenha ocorrido, considerando o intervalo entre os anos de 2014 e 2016. A forma de ingresso dos alunos na instituição no ensino médio se dá no início da primeira série e a maioria dos professores investigados era do quadro efetivo da instituição, com admissão via concurso. ${ }^{9}$

\section{RESULTADOS E DISCUSSÃO}

$\mathrm{Na}$ amostragem com os alunos, a abordagem direta sobre o conceito de plágio levou a resultados que guardam semelhanças com aqueles indicados na survey com os professores (SANTOS et al., 2017). Como pode ser observado nas Figuras 6 e 7 , o percentual de alunos que concorda com as duas primeiras assertivas do questionário, 62,30\% e 70,73\%, respectivamente, se assemelha àqueles associados aos dos professores: $59,52 \%$ concordou com a primeira assertiva e $88,10 \%$, concordou com a segunda (SANTOS et al., 2017). 


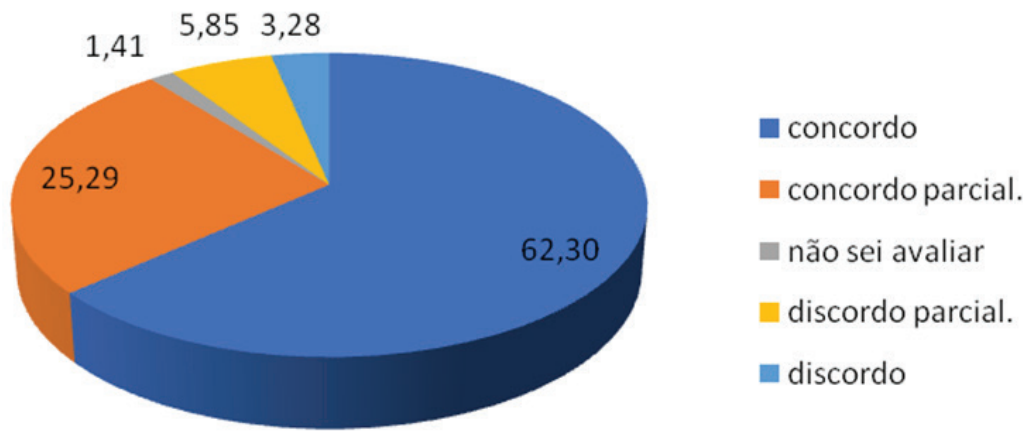

Figura 6. Percentual dos alunos respondentes para cada opção de resposta oferecida para a assertiva: $A$ utilização de ideias do outro e a apropriação das mesmas sem a devida atribuição à fonte/autoria é plágio.

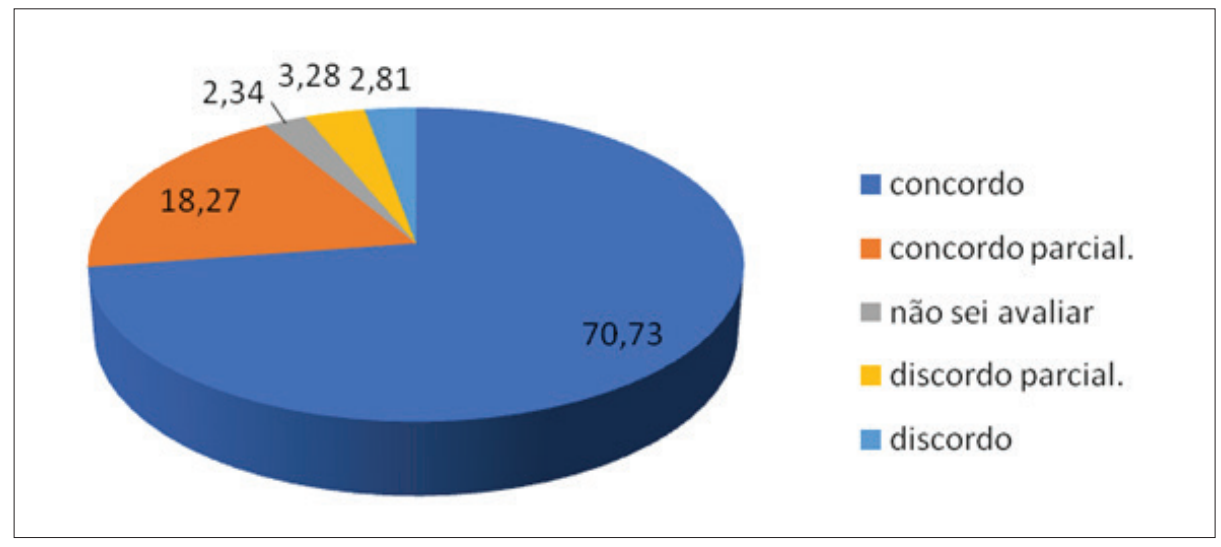

Figura 7. Percentual dos alunos respondentes para cada opção de resposta oferecida para a assertiva: A utilização da produção intelectual escrita do outro (frases/trechos de parágrafos, textos completos) e a apropriação da mesma sem a devida atribuição à fonte/autoria é plágio.

Quando questionados se a cópia integral de textos da Internet - o que chamamos de clonagem - não seria plágio se citássemos a fonte, os alunos apresentaram resultados um pouco diferentes daqueles verificados em survey com os professores. Enquanto 41,46\% dos professores concordaram integralmente ou parcialmente com a assertiva e 51,22\% discordaram totalmente ou parcialmente (SANTOS et al., 2017), com os alunos o padrão se mostrou diferente. Dentre esses, $71,43 \%$ concordou ou concordou parcialmente e $21,32 \%$ discordou ou discordou parcialmente (Figura 8). 


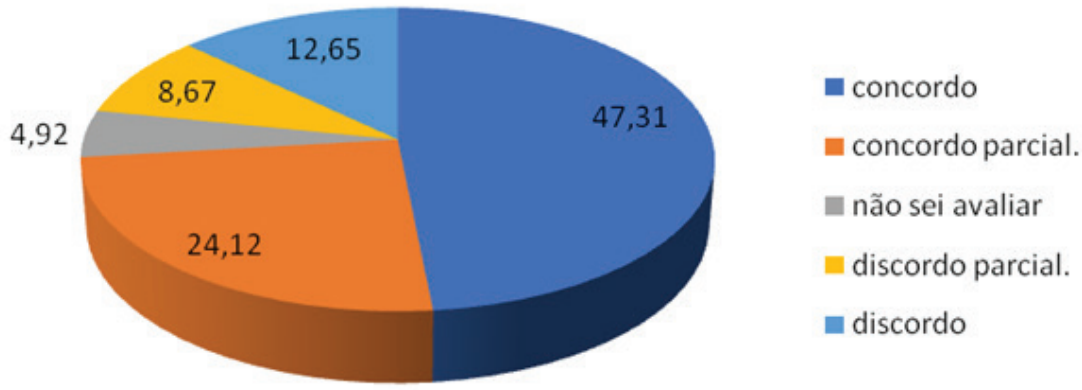

Figura 8. Percentual dos alunos respondentes para cada opção de resposta oferecida para a assertiva: A cópia integral ("clonagem") de textos da internet não é plágio caso eu cite a fonte.

Se os professores amostrados parecem ter dúvidas com relação a esse aspecto, o que pode ser verificado pelos resultados de pesquisa anterior na mesma instituição (SANTOS et al., 2017), os alunos parecem estar mais convictos que a citação da fonte exclui qualquer forma de plágio - seja para o texto completo ou partes dele, como pode ser observado pelos resultados da questão 4, aplicada aos alunos (Figura 9)

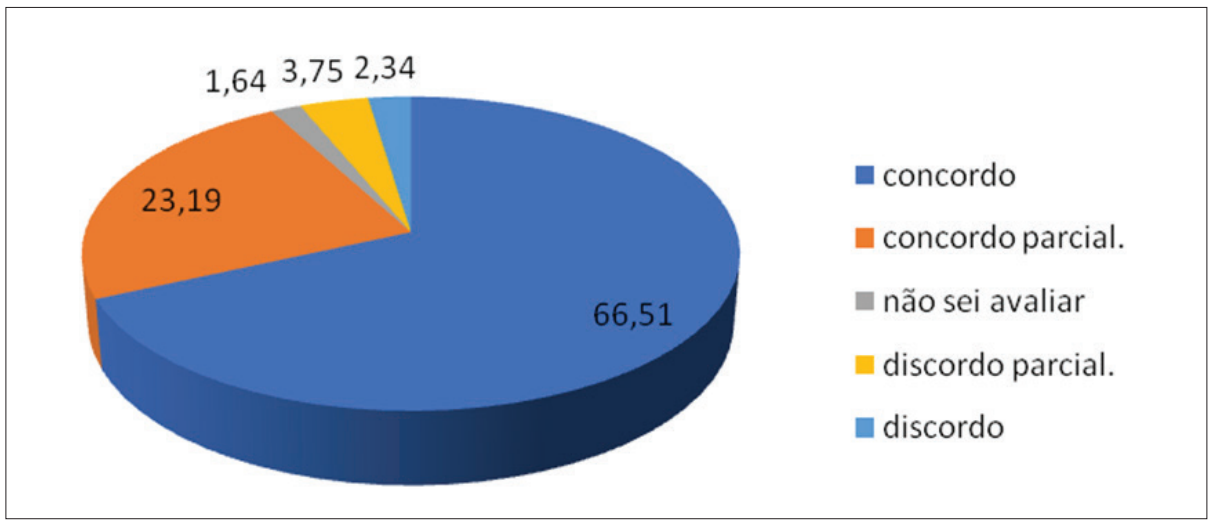

Figura 9. Percentual dos alunos respondentes para cada opção de resposta oferecida para a assertiva: A cópia parcial de textos frases, trechos de parágrafos ou parágrafos inteiros da internet não é plágio caso eu cite a fonte.

Esses resultados nos remetem à pesquisa realizada, também com alunos de ensino médio, por Sisti (2007). Em sua investigação, o autor compara o percentual de alunos que, assumidamente, cometem plágio aos que afirmam que sempre citam a fonte de suas pesquisas. Embora não seja possível afirmar que, aproximadamente, $54 \%$ dos respondentes tenham como prática a cópia integral (clonagem) ou parcial de textos, essa possibilidade não pode ser descartada. 
Verificando os dados oriundos do questionário aplicado aos docentes, observamos que, 82,92\% (SANTOS, 2018) desses docentes concordam integralmente ou parcialmente com o fato da cópia parcial da fonte não ser plágio, caso haja citação dessa fonte. Ou seja, se os professores amostrados têm dúvidas sobre a "clonagem" de textos ser ou não plágio, essa percepção muda quando o foco é a cópia parcial de trechos. O mesmo ocorre com a percepção dos alunos.

Dúvidas sobre plágio textual também foram manifestadas por cientistas brasileiros em estudo anterior (VASCONCELOS et al. 2009). Em publicação do US ORI, intitulada "Avoiding plagiarism, self-plagiarism, and other questionable writing practices: A guide to ethical writing", Roig (2015), apesar de deixar clara a necessidade do uso das aspas para a cópia de trechos, também ressalta que há uma percepção equivocada sobre essa prática. O mesmo autor (ROIG, 2015, p. 7, tradução nossa), citando Julliard (1993), relata que

Embora as evidências indiquem que a maioria dos autores, incluindo estudantes universitários, conhece regras sobre o uso de aspas, o plágio de texto é provavelmente o tipo mais comum de plágio. Por exemplo, alguns autores parecem acreditar que, desde que haja uma citação, é aceitável usar texto literal de outra fonte sem precisar colocar o material emprestado entre aspas.

Diante do exposto, parece razoável supor que a fragilidade sobre o conceito de plágio demostrado pelos docentes em pesquisa anterior (SANTOS et al., 2017) possa estar refletida, de alguma forma, na percepção que os alunos têm sobre a questão. Entretanto, a prática de plágio não seria vista como algo corriqueiro para os alunos amostrados. Para a assertiva 5, o texto usado é um fragmento de um documento da Ordem dos Advogados do Brasil (OAB), de 2010. Como indicado na Figura 10, $55,50 \%$ dos respondentes discordam ou discordam parcialmente, enquanto $38,87 \%$ concordam ou concordam parcialmente com a assertiva extraída do documento.

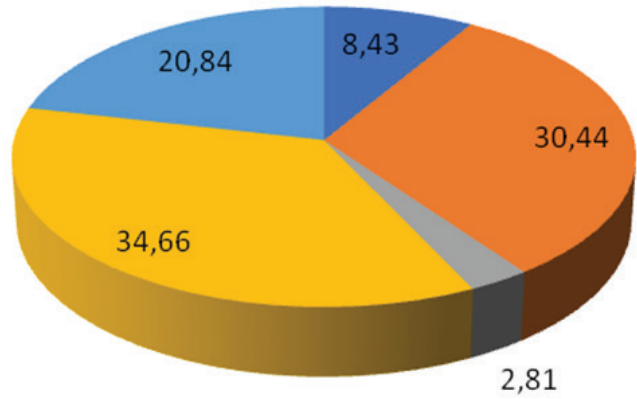

concordo

concordo parcial.

não sei avaliar

discordo parcial.

discordo

Figura 10. Percentual dos alunos respondentes para cada opção de resposta oferecida para a assertiva: "Diante de uma tarefa de pesquisa [os alunos] não leem sobre o assunto, não raciocinam... Apenas copiam e colam textos de terceiros da Internet.". (Documento da Ordem dos Advogados do Brasil - OAB - que discute o crescimento da prática de plágio no ensino médio e superior, 2011). 
Como essa assertiva foi apresentada apenas no questionário usado na survey com os alunos, não podemos comparar diretamente os resultados advindos dela com aqueles da survey dos professores. Entretanto, esses últimos parecem demonstrar consenso em relação à frequência com que os alunos cometem plágio. Entre os professores, $41,46 \%$ dos respondentes indicam que seus alunos quase sempre cometem plágio ao produzirem um trabalho escrito para a sua disciplina, enquanto, 39,02\%, constata que isso ocorre às vezes (SANTOS et al., 2017).

Pesquisas sobre a incidência de plágio entre estudantes de ensino médio registradas na literatura ganharam fôlego a partir da década de 1990. Para esse segmento, entretanto, há maior ocorrência de estudos envolvendo o que os autores nomeiam genericamente de "cheating". Quando os trabalhos fazem referência direta ao ato de plagiar, esse em geral é frequente por parte dos alunos. McCabe e Katz (2009), em um estudo com alunos de terceiro e quarto anos, em 22 escolas públicas americanas constataram que 59\% desses estudantes já tinham cometido plágio. No relatório de 2012 do "Josephson Institute of Ethics", 32\% dos alunos participantes da survey (foram investigados mais de 23.000 estudantes) reconheceram que copiaram documentos da Internet para atender à alguma solicitação de trabalho escolar (SANTOS et al., 2017). Ma et al. (2007, p.76, tradução nossa), em uma pesquisa qualitativa que incluiu um grupo de 36 estudantes, verificaram que

Entre os 36 estudantes participantes dos grupos focais, cerca de dois terços admitiram que já viram alguém que conheciam trapacear por meio da internet. Quase um terço deles relatou ter obtido soluções online para trabalhos de casa sem terem digerido a informação. Nove estudantes também relataram que às vezes ficavam online para copiar e colar artigos [material da Internet] e apresentá-los como seus.

O fato de uma maior parte dos alunos amostrados rejeitar a ideia que "apenas copiam e colam textos de terceiros da Internet”, talvez tenha relação direta com os resultados verificados para a penúltima pergunta do questionário aplicado. Diante da assertiva que abordava a orientação recebida dos professores sobre como evitar o plágio em trabalhos de pesquisa - No ensino médio eu recebi informações de meus professores sobre como evitar o plágio em trabalhos de pesquisa - apenas 25,99\% dos respondentes disse que isso nunca ou raramente aconteceu (Figura 11). O quanto as orientações oferecidas pelos professores, ao longo de todo o ensino médio, poderiam estar refletidas em uma menor percepção por parte dos alunos sobre o que é cópia? 


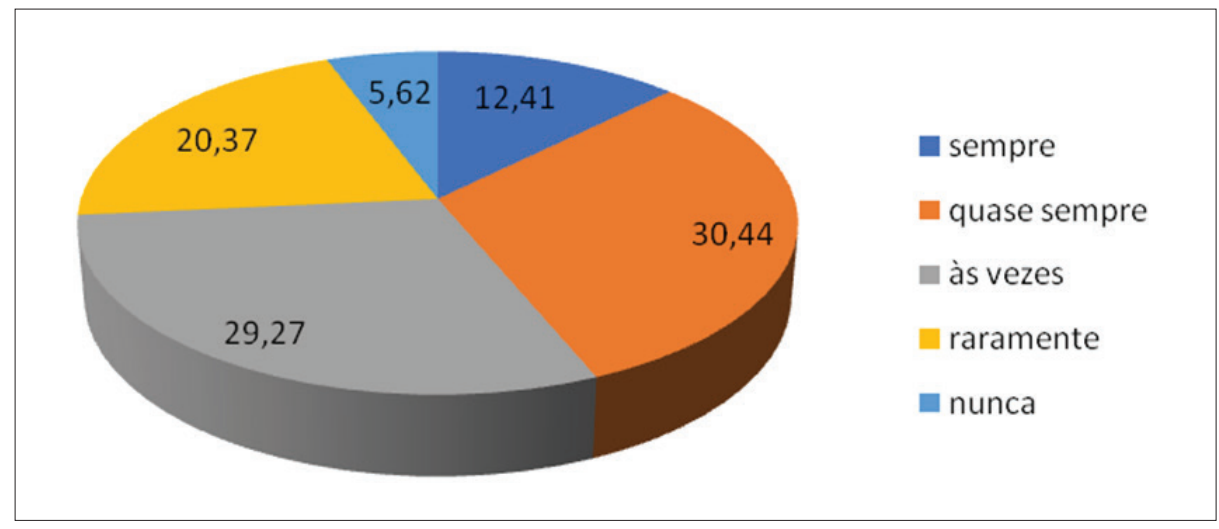

Figura 11. Percentual dos alunos respon dentes para cada opção de resposta oferecida para a assertiva: No ensino médio eu recebi informações de meus professores sobre como evitar o plágio em trabalhos de pesquisa.

A orientação aos estudantes, de modo que tenham uma melhor compreensão do que é o plágio e possam estabelecer uma relação, talvez mais segura, com o uso de fontes bibliográficas das quais se apropriam encontram respaldo em Hall (2005). Esse autor considera que é preciso desenvolver políticas que visem reduzir o plágio, de acordo com quatro princípios. Entre eles estariam os que ele chamou de pedagógicos, o que incluiria atividades de orientação aos estudantes, por meio do desenvolvimento de materiais e recursos específicos. A importância de trazermos já para o nível do ensino médio a discussão sobre a condução adequada de uma pesquisa é destacada por Dias (2017) e Grinnell et al. (2017). Essa ação estimularia o aluno a conhecer o processo de construção de um texto científico, incluindo informações sobre paráfrase e referenciamento, no âmbito de uma produção autoral.

Entretanto, como bem pontua Park, (2003, p. 473), "plagiarism is not a new phenomenon", sugerindo um senso comum de que a Internet favorece essa prática, o que é consistente com Ma et al. (2007). Nesse trabalho, observa-se que os estudantes consideram que não há nenhum problema em "copiar-colar" da Internet, já que todos o fazem e, com pouco esforço. No trabalho de Ma et al (2007, p.77), "students reported their copying and pasting as excitedly as when they were talking about shopping online or chatting online. In their eyes, those things were not that different."

A última questão da survey com os alunos apresenta novamente um aspecto que também já tinha sido abordado na pesquisa anterior com os professores (SANTOS et al., 2017). Tratamos do tema "O ensino de biologia, física e química na escola estimula mais o desenvolvimento da criatividade do que a repetição por parte do aluno." Os resultados indicam falta de consenso entre os alunos em relação a esse aspecto. Entre os amostrados, 41,69\% concordaram ou concordaram parcialmente com a assertiva, enquanto, 47,07\% discordaram na mesma proporção (Figura 12). 


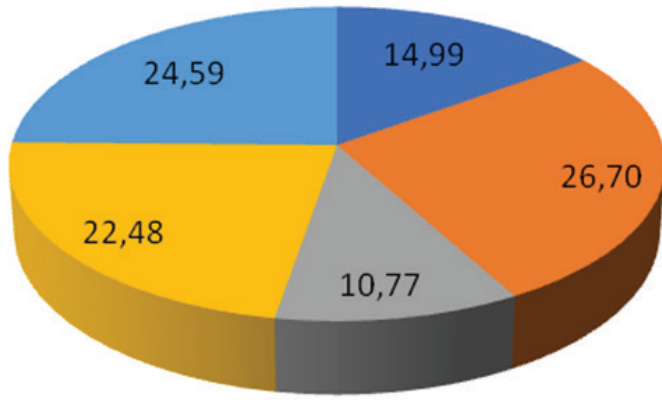

n concordo

concordo parcial.

não sei avaliar

discordo parcial.

discordo

Figura 12. Percentual dos alunos respondentes para cada opção de resposta oferecida para a assertiva: 0 ensino de biologia, física e química na escola estimula mais o desenvolvimento da criatividade do que a repetição por parte do aluno.

No caso dos professores, a pesquisa anterior indicou que 61,9\% dos respondentes discordam totalmente ou parcialmente que há mais estímulo à criatividade do que à repetição (SANTOS et al., 2017). Esses padrões de resposta dos alunos e dos professores refletem, em parte, o que indica a professora Myriam Krasilchik (2000, p. 87):

A tendência de currículos tradicionalistas ou racionalistas acadêmicos, apesar de todas as mudanças, ainda prevalecem não só no Brasil, mas também nos sistemas educacionais de países em vários níveis de desenvolvimento. Assumindo que o objetivo dos cursos é basicamente transmitir informação, ao professor cabe apresentar a matéria de forma atualizada e organizada, facilitando a aquisição de conhecimentos.

Os resultados da pesquisa com os alunos, entretanto, sugerem que eles não apresentam a mesma convicção, o que levanta um questionamento: por que aproximadamente $40 \%$ dos respondentes percebe o ensino de Biologia, Física e Química estimulando mais a criatividade do que a repetição na escola? Se, como afirmamos em Santos et al. (2017, p. 764), "it is well known that repetition and memorization are part of the educational environment", que fatores estariam permitindo uma visão diferenciada por parte desses estudantes? Por que a maioria dos alunos não ratificou essa percepção, assim como ocorrido com os professores? Por que observamos um padrão de resposta mais dividido entre os alunos?

Refletindo sobre essa questão, primeiramente precisamos considerar que entendemos que, apesar das assertivas apresentadas aos professores e aos alunos não serem exatamente iguais, ${ }^{10}$ elas tratam do mesmo aspecto, ou seja, a ênfase na criatividade ou na repetição no ensino de Biologia, Física e Química. Pela formulação do texto apresentado aos professores, entretanto, é possível que esses docentes tenham dado suas respostas baseadas numa visão mais ampla do ensino - uma visão incluindo uma perspectiva que teriam sobre o ensino no país, de forma geral. 
O texto da assertiva apresentada aos alunos, entretanto, sugere uma realidade mais particular, aquela da escola em que frequentam e não instituições aleatórias ou genéricas. Mesmo considerando que não podemos assegurar que grande parte dos alunos teve essa percepção, há uma possibilidade viável para essa consideração, dado o padrão de ingresso dos alunos no colégio em estudo. Se considerarmos aqueles que entraram na escola na $1^{a}$ série do primeiro segmento do ensino fundamental, podemos ter entre os respondentes, alunos que estão na escola há mais de 10 anos. Porém, mesmo para aqueles que ingressaram somente no ensino médio, esse tempo não será menor que 3 anos. Diante desse tempo de estudo na mesma escola, e da forma como foi apresentada a assertiva, é possível que os alunos possam ter dado suas respostas muito mais baseadas na realidade por eles vivida no colégio do que considerando a "instituição escola", genericamente.

Diante dessas ponderações, o padrão de respostas dos alunos talvez tenha refletido uma dualidade: o fato dos alunos terem ciência de que estudam em um dos colégios considerados como uma das "ilhas de excelência", com um corpo docente de qualidade, onde seus alunos podem desenvolver projetos e obtêm bons resultados em avaliações nacionais e internacionais. ${ }^{11}$ Por outro lado, há o fato de que esse mesmo colégio, seus docentes, também estão inseridos em um sistema mais amplo de ensino que, em grande parte, não privilegia "a ideia de que a educação em ciências deveria ter como foco inicial o desenvolvimento de atitudes mais gerais de curiosidade, observação dos fatos e busca de relações causais" (SCHWARTZMAN; CHRISTOPHE, 2010).

\section{CONSIDERACְÕES FINAIS}

Os dados apresentados e discutidos neste artigo diminuem a enorme lacuna que a literatura acadêmica apresenta quando se trata da relação entre educação e plágio - acentuada no âmbito da educação em ciências. Este estudo reitera a provocação já feita em (SANTOS et al., 2017) - que a discussão sobre o plágio, cada vez mais, deve ir além da esfera da integridade acadêmica, "ampliando a relação de práticas de plágio com práticas pedagógicas que, indiretamente, incentivam a cópia” (SANTOS, 2018, p.111). Pela ainda escassa literatura disponível sobre o tema, no âmbito da educação em ciências, há um longo caminho a ser percorrido no que tange ao estímulo, por meio de claras iniciativas, a boas práticas de pesquisa na educação básica.

Para o Brasil, esse é mais um desafio que deve entrar na agenda de educadores e gestores. Como aborda Chaurasia (2016), para a ciência da Índia (país emergente como o Brasil), alguns dos problemas que temos podem começar a ser atacados quando os pesquisadores ainda estão na escola. Apesar deste estudo oferecer uma perspectiva sobre o plágio no âmbito do ensino de ciências na educação básica, não podemos deixar de ressaltar que os alunos pesquisados estão inseridos em uma instituição federal brasileira, com peculiaridades que não permitem generalização dos resultados. Um outro ponto que merece atenção é que, embora a amostra seja representativa dos dois campi amostrados, as percepções dessa população sobre o plágio na escola podem estar influenciadas por um "desirability bias", uma espécie de viés social que pode ter tornado suas respostas sobre o plágio mais conservadoras. 
Essas limitações podem ser encaradas como motivadoras para estudos adicionais, não apenas com população de estudo mais ampla, mas também mais diversa.

Há uma urgência, que nos parece justificada, sobre abordagens dessa temática em nosso país. Independentemente dessa necessidade, estes resultados sugerem a importância de que investigações sobre as percepções e atitudes sobre a prática de plágio na educação básica explorem as perspectivas docente e discente. Essa combinação potencializa uma compreensão mais aprofundada do problema, independentemente do tamanho do estudo.

\section{AGRADECIMENTOS}

Agradecemos a colaboração de Mariana Dias Ribeiro, atualmente doutoranda do Programa de Educação, Gestão e Difusão em Biociências do IBqM/UFRJ, na aplicação do questionário aos alunos e na tabulação dos dados. Este estudo foi possível com o apoio da CAPES ao doutorado associado.

\section{REFERÊNCIAS}

ANDERSON, M. S.; STENECK, N. H. The problem of plagiarism. Urologic Oncology: Seminars and Original Investigations, v. 29, n. 1, p. 90-94, 2011.

ARDA, B. Publication Ethics from the Perspective of PhD Students of Health Sciences: A Limited Experience. Science and Engineering Ethics, v. 18, n. 2, p. 213-222, 2012.

BRETAG, T. Contract cheating will erode trust in science. Nature, v. 574, 31 October, 2019.

CEBRIÁN, M.; ALFONSECA, M.; ORTEGA, A. Towards the validation of plagiarism detection tools by means of grammar evolution. IEEE Transactions on Evolutionary Computation, v. 13, n. 3, p. $477-485,2009$.

CHARTIER, R. As práticas da escrita. In: CHARTIER, R (org.). História da vida privada - da renascença ao século das luzes. São Paulo: Companhia das Letras, 2009. p. 113-162.

CHAURASIA, A. Stop teaching Indians to copy and paste. Nature, v. 534, n. 7609, p. 591, 2016.

CHRISTOFE, L. Intertextualidade e plágio: questões de linguagem e autoria. Campinas, 1996. 193 f. Tese (Doutorado em Linguística) - Instituto de Estudos da Linguagem, Universidade de Campinas, 1996.

CHUDA, D. et al. The issue of (software) plagiarism: A student view. IEEE Transactions on Education, v. 55, n. 1, p. 22-28, 2012.

CUNHA, A. G. da. Dicionário etimológico Nova Fronteira da língua portuguesa. $2^{\mathrm{a}} \mathrm{ed}$. Rio de Janeiro: Nova Fronteira, 1997. 839 p.

DE GROOTE, S. L.; RASZEWSKI, R. (2012). Coverage of Google Scholar, Scopus, and Web of Science: A case study of the h-index in nursing. Nursing Outlook, v. 60, n.6, p. 391-400.

DIAS, W. T. Há espaço para a construção autoral nos trabalhos de pesquisa escolar. Rio de Janeiro, 2017. 260 f. Tese (Doutorado em Educação) - Programa de Pós-graduação em Educação do Departamento de Educação do Centro de teologia e Ciências Humanas, PUC-Rio, 2017. 
DINIZ, D; TERRA, A. Plágio Palavras Escondidas. Brasília: LetrasLivres; Rio de Janeiro: Editora Fiocruz, 2014. 196p.

DOMIN, C.; POHL, H.; KRAUSE, M. Improving Plagiarism Detection in Coding Assignments by Dynamic Removal of Common Ground. In: PROCEEDINGS OF THE 2016 CHI CONFERENCE EXTENDED ABSTRACTS ON HUMAN FACTORS IN COMPUTING SYSTEMS - CHI EA '16, 2016, San Jose, California, USA. p. 1173-1179.

GRINNELL, F. Research Integrity and Everyday Practice of Science. Sci Eng Ethics, v. 19, p. 685-701, 2013.

GRINNELL, F. et al. High school science fair and research integrity. PLoS ONE, v. 12, n. 3, p. 1-15, 2017.

HALL, J. Plagiarism Across the Curriculum: How Academic Communities Can Meet the Challenge of the Undocumented Writer. ATD. Across the disciplines. Interdisciplinary perspectives on language, learning and academic writing, v. 2, 2005.

HEITMAN, E.; LITEWKA, S. International perspectives on plagiarism and considerations for teaching international trainees. Urologic Oncology: Seminars and Original Investigations, v. 29, n. 1, p. 104-108, 2011.

ISRAEL, G. D. Determining sample size. Tech. Rep. No. PEOD-6. Florida: University of Florida, Institute of Food and Agricultural Sciences, 1992. Revised 2003.

JI, JEONG-HOON; WOO, GYUN; CHO, Hwan-Gue. A Source Code Linearization Technique for Detecting Plagiarized Programs. IN: 12TH ANNUAL CONFERENCE ON INNOVATION \& TECHNOLOGY IN COMPUTER SCIENCE EDUCATION, 2007, Dundee, Scotland. p. 73-77.

JULLIARD, K. Perceptions of plagiarism in the use of other authors' language. Family Medicine. v. 26, p. 356-360, 1993.

KOOGAN, A.; HOUAISS, A. Enciclopédia e dicionário ilustrado. Rio de Janeiro: Delta, 2000.

KRASILCHIK, M. Reformas e realidade: o caso do ensino das ciências. São Paulo em Perspectiva. v.14, n.1, São Paulo Jan./Mar. 2000. Disponível em: <http://www.scielo.br/scielo.php?script=sci_ arttext\&pid=S0102-88392000000100010\&lng=pt\&tlng=pt $>$. Acesso em 02 fev 2018.

KROKOSCZ, M. Outras palavras sobre autoria plágio. São Paulo: Atlas, 2015. 173 p. 1730.

LIKERT, R; ROSLOW, S; MURPH, G. A Simple and Reliable Method of Scoring the Thurstone Attitude Scales, The Journal of Social Psychology, v. 5, n. 2, p. 228-238, 1934.

LIU, X.; XU, C.; OUYANG, B. Plagiarism Detection Algorithm for Source Code in Computer Science Education. International Journal of Distance Education Technologies, v. 13, n. 4, p. 29-39, 2015.

MA, H. et al. An empirical investigation of digital cheating and plagiarism among middle school students. American Secondary Education, v. 35, n. 2, p. 69-83, 2007.

MADDOX, J. Plagiarism is worse than mere theft. Nature, v. 376, n. 6543, p. 721, 31 ago 1995.

MARTINS, R. B. Do papel ao digital: a trajetória de duas revistas científicas brasileiras. Rio de Janeiro, 2003. 182 f. Dissertação (Mestrado em Ciência da Informação) - Instituto Brasileiro de Informação em Ciência e Tecnologia (IBICT), Universidade Federal do Rio de Janeiro, 2003. 
Uma visão conservadora sobre o plágio? Reflexões a partir de um levantamento sobre a perspectiva de uma população de alunos brasileiros do Ensino Médio

McCABE, D.; KATZ, D. Curbing Cheating. Tech Directions, v. 69, n. 3, p. 32-34, 2009.

MERTON, R. K. The Matthew Effect in Science. Science, v. 159, n. 3810, p. 56-63, 1968.

MONTGOMERY, K; OLIVER, A. L. Shifts in Guidelines for Ethical Scientific Conduct: How Public and Private Organizations Create and Change Norms of Research Integrity. Social Studies of Science, v. 39, n.1, p. 137-155, 2009.

MOSKOVITZ, C. Self-Plagiarism, Text Recycling, and Science Education. BioScience, v. 66, n. 1, p. 5-6, 2015.

OFFICE OF SCIENCE AND TECHNOLOGY POLICY. Federal Research Misconduct Policy. 2000. Disponível em: < https://ori.hhs.gov/federal-research-misconduct-policy> Acesso em: 31 out 2017.

PARANAGUÁ, P.; BRANCO, S. Direitos Autorais. Rio de Janeiro: Editora FGV, 2009. 144 p.

PARK, C. In (Other) People's Words:Plagiarism by University Students -Literature and lessons. Assessment and Evaluation in Higher Education, v. 28, n. 5, p. 471-488, 2003.

ROIG, M. Avoiding plagiarism, self-plagiarism, and other questionable writing practices: A guide to ethical writing. The Office of Research Integrity (ORI), 2015. Disponível em: <https://ori. hhs.gov/avoiding-plagiarism-self-plagiarism-and-other-questionable-writing-practices-guide-ethicalwriting>. Acesso em: 20 jan 2017.

SANTOS, C. C. Uma perspectiva sobre o plágio na educação em ciências a partir de percepções e atitudes de professores e alunos de uma instituição federal no Brasil. Rio de Janeiro, 2018. 221 f. Tese (Doutorado) - Programa de Pós Graduação em Química Biológica - Área de Concentração: Educação, Gestão e Difusão em Biociências, Universidade Federal do Rio de Janeiro, 2018.

SANTOS, C. C. et al. Going beyond academic integrity might broaden our understanding of plagiarism in science education: A perspective from a study in Brazil. Anais Academia Brasileira de Ciências, v. 89, n. 1, p. 757-771, May 2017.

SCHWARTZMAN, S.; CHRISTOPHE, M. A educação em ciências no Brasil. Instituto do Estudo do Trabalho e Sociedade, 2010. 119p. Disponível em: < http://www.abc.org.br/IMG/pdf/ doc-210.pdf>. Acesso em: 20 jan 2018.

SISTI, D. A. How do high school students justify Internet plagiarism? Ethics and Behavior, v. 17, n. 3, p. 215-231, 2007.

SKANDALAKIS, J. E.; MIRILAS, P. Plagiarism. The Archives of Surgery, v. 139, n. 9, p. 1022 1024,2004

SOUZA, C. M. Entre a proteção da propriedade e a manutenção do monopólio: o debate sobre a regulamentação do mercado de livros na Inglaterra de 1662 a 1774. São Paulo, 2013. 246 f. Dissertação (Mestrado em História) - Faculdade de Filosofia, Letras e Ciências Humanas, Universidade de São Paulo, 2013.

STENECK, N. H. Confronting misconduct in Science in the 1980s and 1990s: what has and has not been accomplished? Science and Engineering Ethics, v. 5, n. 2, p. 161-176, 1999.

VASCONCELOS, S. et al., Discussing Plagiarism in Latin American Science: Behind the Times? EMBO Reports, v. 10, n.7, p. 677-682, 2009. 
ZANINI, L. E. de A. Direito de autor em perspectiva histórica. Revista CEJ, v. 18, n. 63, p. 15-24, maio/ago. 2014.

ZANINI, L. E. DE A. Notas sobre plágio e a contrafação. Revista Brasileira de Direito Civil, , v. 10, p. 44-60, out/dez 2016.

\section{NOTAS}

1 Este manuscrito é um recorte, com edições, modificações e ajustes, feitos em colaboração entre as coautoras, de uma parte da tese de doutorado da primeira autora, orientada pela segunda. A tese está listada nas referências.

2 Esta ferramenta permite acompanhar a variação com que transita um termo escolhido na base de dados do Google Books, em um determinado período, que pode ser a partir de 1500 até 2008, e em um idioma especificado. Optamos por observar essa tendência a partir de 1960. A opção por esse limite inferior baseou-se no fato desta década ter presenciado o desenvolvimento das tecnologias de informação, que repercutiram, por exemplo, no início da informatização de referências, em meados de 1960 (MARTINS, 2003). Também, segundo Sisti (2007), a partir da publicação do artigo de William Bowers em 1964, "the prevalence of academic transgressions has been systematically researched" (p. 216).

3 Como essas bases têm diferentes opções de buscas, preferimos fixar, em todas, a pesquisa pelo termo de interesse apenas no título, sem limitar os demais filtros, também dentro do período de 1960 e 2008.

4 "Scopus is a multidisciplinary database, with 44.5 million records (as of January 2012) and more than 18,500 peer-reviewed journal titles in the life sciences, social sciences, health sciences, and physical sciences. In addition to journal articles, there are also conference papers, trade publications, book series, records from the scientific web search engine, Scirus, and patent records.". (DE GROOTE; RASZEWSKI, 2012, p.393).

5 "WOS is a multidisciplinary database known for its cited reference coverage from Thomson Reuters [...] It indexes more than 10,000 journals in 256 categories in arts and humanities, sciences, and social sciences." (DE GROOTE; RASZEWSKI, 2012, p. 393.).

6 "GS is a search engine that searches the scholarly literature, including the full text of many journals. It primarily searches academic papers from most major academic publishers and repositories worldwide, including both free and subscription sources. [...] Google does not specifically list the sources of its data but it is designed to be as comprehensive as possible." (DE GROOTE; RASZEWSKI, 2012, p. 393 e 394).

7 Proceedings do V Brazilian Meeting on Research Integrity, Science and Publication Etbics, 2018, https:// researchintegrityjournal.biomedcentral.com/articles/10.1186/s41073-020-0090-6

8 Um resumo com resultados parciais apresentados neste artigo foi publicado nos Proceedings do IV Brazilian Meeting on Research Integrity, Science and Publication Ethics, 2016, https:/ / researchintegrityjournal. biomedcentral.com/articles/10.1186/s41073-017-0035-x

9 Entre os anos de 2014 e 2016, houve admissão de novos docentes efetivos de Biologia a partir de julho de 2015 e de Física e Química, a partir do novembro de 2016.

10 A assertiva que foi apresentada aos professores foi a seguinte: "No Brasil a prática didáticopedagógica do professor de biologia, física e quimica estimula mais o desenvolvimento da criatividade do que a repetição por parte do aluno." (SANTOS, 2018). 
Uma visão conservadora sobre o plágio? Reflexões a partir de um levantamento sobre a perspectiva de uma população de alunos brasileiros do Ensino Médio

11 Para maiores detalhes, consultar:

https://theintercept.com/2016/12/08/estudantes-federais-tem-desempenho-coreano-em-cienciasmas-mec-ignora/

https://novaescola.org.br/conteudo/3398/resultado-pisa-boas-noticias-brasil

https://www.cp2.g12.br/ultimas_publicacoes/220-not\%C3\%ADcias2016/5435-cpii-lideraranking-de-melhores-escolas-p $\%$ C3\%BAblicas-do-rj-no-enem-2015.html

http://agenciabrasil.ebc.com.br/educacao/noticia/2016-10/enem-federais-militares-e-tecnicassao-publicas-com-melhor-desempenho

Submetido em 11/04/2019

Aprovado em 07/11/2019

Contato:

Christiane Coelho Santos

Colégio Pedro II

Campo de São Cristóvão, $\mathrm{n}^{0} 177,3^{\mathrm{a} a n d a r \mid}$ Campo de São Cristóvão

CEP 20.921-903. Rio de Janeiro, RJ - Brasil 